\title{
COMPETITIVE MARKET OPPORTUNITIES FOR TELECOMMUNICATIONS SERVICES IN BULGARIA
}

\author{
R. Otuzbirov*, G. Aleksiev \\ Faculty of Economics, Trakia University, Stara Zagora, Bulagria
}

\begin{abstract}
The mobile services market in the country is overregulated facing fierce competition and falling prices. What is more, there is an evident low consumption for individual customers and business clients. According to mobile operators' statistics for the year 2014 Mtel holds 39\% of the mobile market, followed by Telenor with $37 \%$ and $24 \%$ Vivacom. On the fixed market for individual clients Vivacom is the leader with $20 \%$, followed by Blizoo (15\%), Bulsatkom (12\%), Mtel (7\%) and others (46\%) - all in all more than 250 operators.

Companies seem to agree on the factors that affect their financial performance for a second consecutive year. The reduction of tariffs for termination of traffic in mobile networks imposed by the regulator in several steps, as well as the decrease in roaming tariffs adopted by the EU are among the main reasons. Along with these external factors, there are other influential facts such as the slow economic development, the declining incomes of the majority of the population, the failure of small and mediumsized businesses, as well as a number of internal problems the mobile operators might experience. The combination of fixed and mobile communication is becoming a key requirement of the telecommunications market.
\end{abstract}

Key words: telecommunications, market factors, development

\section{INTRODUCTION}

Telecommunications has proven to be one of the keystones for modern society. The information age has made the access to communicational channels a necessity. In such an environment the telecommunication operators "bloom" and there services are in a high demand. In order to balance the market there needs to be a certain amount of competitive organizations, so there can be diversity to the supply meeting that demand.

Although providing an important service to the society the telecommunication sector is heavily regulated due to the technology used to implement the required information channels. Electro-magnetic contamination is an issue with increasing publicity in the last decade. That requires for the government to take a strong position and heavily regulate wireless communication networks.

The institutional regulations and restrictions are always the main concern of all mobile

\footnotetext{
* Correspondence to: Rumen Otuzbirov, Faculty of Economics, Trakia University - Stara Zagora, Studentski grad, 6000 Stara Zagora, Bulagria, 042/699411,E-mail: otuzbirov@uni-sz.bg
}

operators that strive for a freer market with the least amount of obstacles. This can have a double-edged effect duo to bringing new players to the field, which is impossible with the current state of affairs. The government through its regulatory mechanisms restrict the access of new players, in order to reduce the impact of electro-magnetic waves on the populations.

\section{TELECOMUNICATIONS IN BULGARIA}

For the purposes of this paper we will focus on the three largest mobile operators in the country - Mobiltel, Tellenor and Vivacom. In order to analyze their competitiveness and the strategies they implement, a historical review of the sector and its development for the last decade must be presented.

The first telecommunication company in Bulgaria to offer wireless services is Mobiltel, which is founded in 1994 and starts operating in 1995. Its leading position allows the company to implement innovations in the sector and maintain its competitive position (unchallenged for a long period of time) for the best part of the first decade of the 21 century. The development of the sector starts up slow 
due to the economic crisis in the country and by the end of the 90s the operator has around 100 thousand clients. It takes 18 years for the company to build up its network and cover the whole population and fully penetrate the market and fulfil its potential.

In the turn of the new century under a growing social pressure the government held an auction for the rights to create a second parallel wireless communication network in the country. The auction was won by the company Cosmo Bulgaria Mobile, which is owned OTE S.A. and on the 17 of September 2001 the company started operating under the brand name "Globul". In 2005 all of the shares of the company are bought by COSMOTE Group, the largest telecommunication company on the Balkans peninsula. By the end of the decade the new competitor has caught up to the leader "Mobiltel".

In June 2004 the government sold 65\% of BTK's shares - the only government owned Telecommunication Company to the American Advent International investment fund. This have started the process of introducing a third entity to the telecommunications competitive market, by licensing the newly formed Vivatel company in May 2005 to build a mobile telecommunications network - the third one in the country. The merger of BTK and Vivatel in to Vivacom in 2005 has created a powerful competitor with certain advantages, due to the large number of clients of the fixed services that BTK had a monopoly on.

\section{MOBILE COMPETITIVENESS}

The mobile market in Bulgaria has been turbulent one and it only started to settle in the beginning of the $2^{\text {nd }}$ decade of the century. The introduction of a third player in the field has proven to have a positive impact on the market, by forcing the introduction of competitive strategies common to the more developed markets.

In order to analyze the market and its competitiveness in the future a few tasks must be completed:

- Explore the market of telecommunication services in the country.

- Analyze competitive strategies that companies in the sector and apply their success.

- Assess the impact of administrative regulation on the telecommunications market.

- Examine obstacles to market development of telecommunication services in Bulgaria.
Mobile operators continuously increasing their range of services offered, they no longer offer just mobile connectivity. That is why the pace setter of the Bulgarian telecommunications market - Mobiltel chose to purchase the two largest Internet service providers (ISP) in the country - Spectrum Net and Megalan Network. Megalan delivers broadband internet and digital television in Sofia, covering over $65 \%$ of the city. By acquiring it "M-Tel" will start the construction of a nation-wide fiber-optic network. Which should allow each customer to be able to choose a provider that will offer the whole package of services - Internet, television and telephone with a high level of quality.

Megalan and Spectrum Net had revenues of 25.3 million euros combined in 2009 , which earns them before interest, taxes and amortization about 7 million euros and for 2010 the is an expected growth to 9.6 million euros. Through the purchase of both telecom Mobiltel will increase its market share of fixed Internet and fixed telephony. Offering package services will lead to a reduction in user spending as they can benefit from discounts. According to CEO of "M-tel" Andreas Maierhofer the growth of fixed broadband in Bulgaria by 2019 could be $85 \%$.

The combination of fixed and mobile communication is becoming a key requirement of the telecommunications market. This is a trend observed on many local markets by Telekom Austria Group, and is now transforming the competitive environment in Bulgaria. For this reason, the planned acquisition of two fixed internet service is a natural step in the development of any competitive organization.

In comparison to Mobiltel, its biggest competitor Telenor does not offer yet the "Digital TV" and the home Internet service is only available through a special receiver device.

VIVACOM is the main competitor in providing modern telecommunication services - fixed and mobile voice services, optical internet, digital $\mathrm{TV}$, as well as individual telecommunications decisions made custom.

Mobiltel scrambles to invest in new technologies in order to offer the more attractive and advanced services that customers need while trying to reduce the costs. With this investment Mobiltel, tries to strengthen its market position, as well as showed their competitors Telenor and Vivacom their capabilities. 
According to financial reports of the three leading telecoms, new leader is Vivacom which reported in 2013811.9 million lv. revenue, or 5\% less than revenues for 2012. Based on the large decline in revenues of the other two major telecom - Mtel and Globul, the Company has been "at the forefront" of the telecom market in the country. This is due mainly to mobile services for the first time in the history of the company bringing more revenue than traditional fixed services.

Proceeds of Vivacom mobile services in 2013 were 415.9 million $1 \mathrm{v}$., or $5 \%$ more than the revenues from this segment in 2012. According to the company, this is mainly due to steady growth of mobile subscribers to fixed-term contracts during the year. At the same time, increased sales of smart phones and tablets have managed to compensate for reduced regulator termination rates. For the first time the company reported a number of mobile subscribers - 2.6 million at the end of
2013, or $10 \%$ growth compared with 2012. Since Vivacom explain that the number and growth of mobile subscribers reported after changing methodology for reporting of prepaid services, which excludes prepaid customers with no traffic for more than 3 months.

The main income for Vivacom is the subscription fees, for the entire 2013 they amounted to 352 million lv., or $4.6 \%$ growth compared to 2012, due to increased supply of bundled services and the provision of more customer service included in their monthly fee, as well as the net increase in the number of subscribers as a result of optimization of tariffs offered to customers. The company's revenues from outgoing traffic for 2013 are 143.3 million lv. (annual decline of $15.2 \%$ ), mainly due to lower termination rates and competitive pressures, leading to a decline in prices per minute and more included minute in tariffs offered to customers.

\section{Quarterly revenue for the three largest telecommunication companies in Bulgaria}

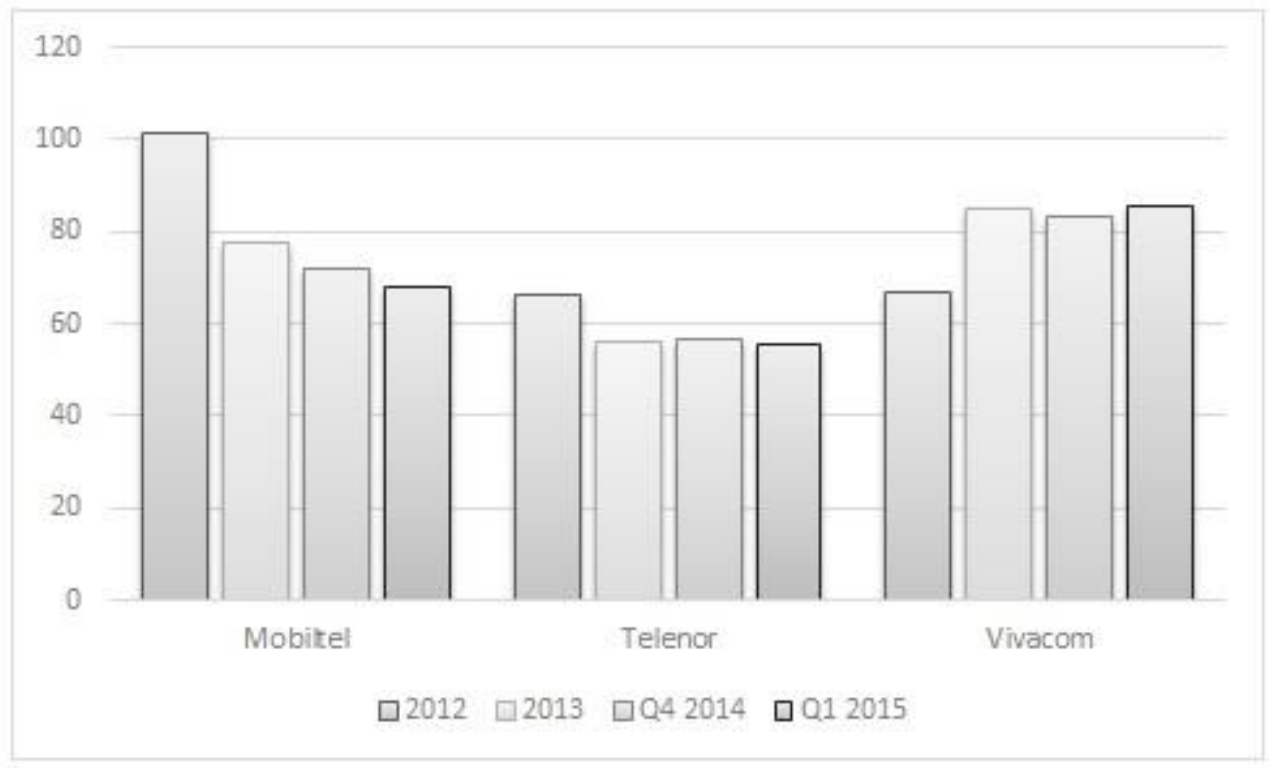

Source: Calculated based on Telenor, Vivacom and Mobiltel yearly reports

\section{GRAPHIC 1.}

Revenues from interconnection lines for 2013 amounted to 60.7 million lv. (down $53.2 \%$ ). From leased lines and data transmission Vivacom received in 2013118.9 million lv., representing an annual decline of $7.5 \%$, mainly due to the migration of customers to lower-cost IP services.

On the Bulgarian market of fixed broadband Internet their main competitors are Blizoo, Mobiltel, Bulsatcom and a significant number of smaller LAN operators. Vivacom is the market leader fixed broadband with a market share of $25 \%$ based on the number of subscribers at 31 December 2012, followed by Blizoo, MobilTel and Bulsatcom.

Mtel's total revenues for 2013 decreased by $14.8 \%$ to 781 million lv. (399.4 m. euros), and only for the fourth quarter of 2013 revenues decreased by $10.3 \%$ to $994 \mathrm{~m}$. euros compared to the same period of 2012. This decline is due to reduced revenues from monthly fees, traffic and revenue for each connection. The latter comes as a result of a reduction in termination rates and the income from monthly fees and traffic is negatively influenced by the lowering 
of prices for subscriptions and prepaid services.

Comparable profit before taxes and amortization EBITDA declined in the last quarter of 2013 by over 25 percent to 31.9 million euros, while for the whole 2013 it was $158.6 \mathrm{~m}$., or $23.5 \%$ lower than that for 2012 . The cost of interconnection and roaming decreased as a result of several con-stringent cuts in termination rates in 2012 and 2013. This decline was offset by an increase in other costs resulting from one-off effects related to the assessment by the management of business risk.

Globul's data for the last two fiscal quarters of 2013 have been restated in accordance with accounting policy of Telenor, which bought the Bulgarian mobile operator in the middle of 2013. The decline is mainly due to rapid increase of termination rates imposed by the regulator on 1 July 2012 and additional steps in January and July 2013. The Bulgarian telecommunications market remains focused on voice services and they continue to form the bulk of the revenue in the sector.

In this environment Telenor's revenue from services and data for the last three months of 2013 grew by $42 \%$ compared to the same period of 2012. In the fourth quarter of 2013 subscribers of services for mobile data increased by $56 \%$ while subscribers of fixed services operator have reached over 250,000.

Revenues from telecommunications products and services for 2013, the three major operators in the country are 2.255 billion lv., or more than $10 \%$ less than what they achieved in 2012. Earnings before taxes, depreciation and amortization also shrank by $6.76 \%$ with a total of 874 million lv. The decline in revenue was the highest in two largest companies that

\section{OTUZBIROV R., et al.}

dominate the mobile market - Mtel and Telenor, which hold $76 \%$ of the mobile customers), while the third mobile operator Vivacom summers a $5.4 \%$ decrease due mainly to the pre-fixed business of the company. Vivacom however managed to raise revenues from the mobile segment and it already brings in more revenues than the traditional fixed services.

Companies are unanimous about the factors that affect their financial performance for the second year in a row, always starting from the reduction of tariffs for termination of traffic in mobile networks imposed by the regulator in several steps and adopted by the EU reduction of roaming tariffs. These external factors are added delayed economic development, declining incomes, failing small and medium companies, and a number of internal disorders in the operators.

One of them is the way of "counting" the number of active subscriptions, the aim was to improve the important for investors in the telecom industry indicators for average monthly revenue per user, which in continues to decline, although it is two times lower than other countries in the region and more than 3 times lower than developed markets in Western Europe. This indicator is calculated on the basis of the intercept of all subscribers and was slightly higher at the end of the year, annual reports and three telecom adopted a new methodology for counting active subscribers. Through it they exclude from "local base" those prepaid cards that are not used for more than three months, and it does not take into account embedded SIM cards in many ATMs, vending machines for food, coffee machines, dispensers and other communications.

Number of mobile subscritions in March 2015 of three largest telecommunication companies in

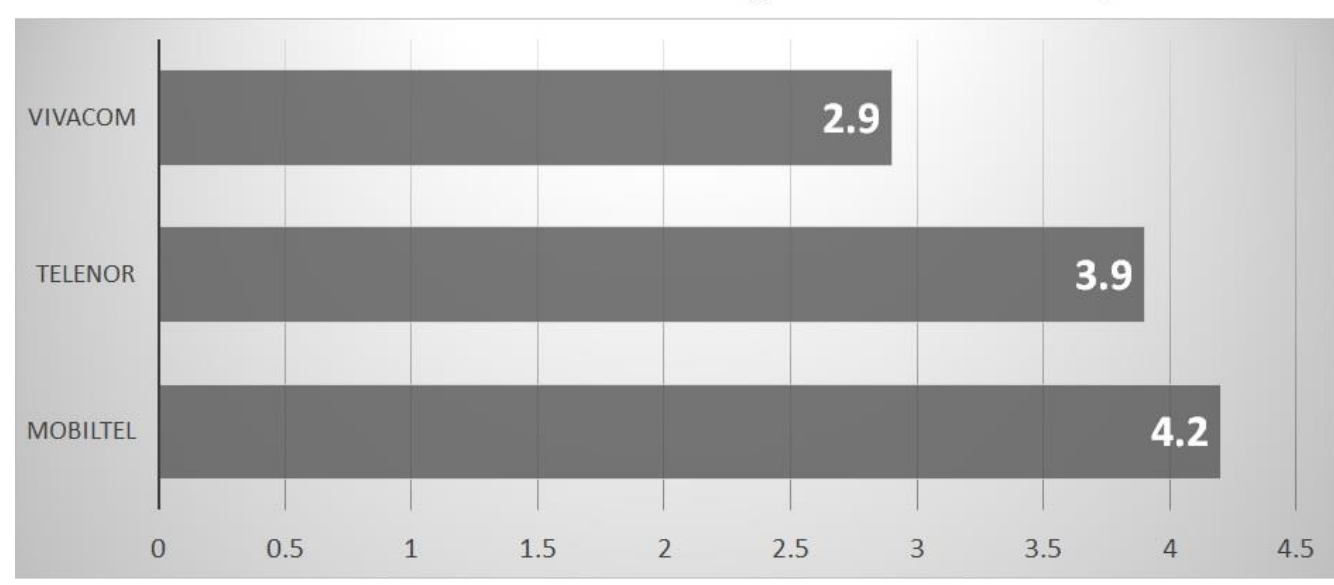

Source: Anual and quarter reports of Telenor, Vivacom and Mobiltel.

GRAPHIC 2. 
Accounting principle for prepaid users was changed - rather than a period of validity of a voucher, they are accounted for active usage and as a result, subscribers who previously considered themselves active as they had a voucher valid for 12 months now are considered active users only if they have used mobile services within the last 3 months. This change has led to a reduction in the number of mobile subscribers of Mtel by 498,000.

For the same reasons Telenor has suffered a reduction of over 600,000 SIM subscription as of the end of June 2013 the company reported 4.6 million subscribers at the end of September following the introduction of the methodology Telenor base of active subscriptions is about 3,9 million. For Vivacom this transformation has excluded around 200,000 subscriptions.

In Mtel however there is a change in the fixed services. "Box Services" ", where home users receive through mobile technology two numbers (one fixed and one mobile), is now reported as one mobile subscription instead of two, as stated in the report of Telecom Austria Group. - This has led to a decrease of total mobile subscriptions 215000 . Integrated telecommunications services for business customers who have used them in fixed lines, but was available and predetermined set of mobile numbers for voice calls also reported a new way. The said mobile numbers so far are "few" mobile subscriptions and Q4 of 2013 they are considered as "purely fixed lines." This change "has removed" more 313,000 mobile subscription base of Mtel and to the fixed access lines were added 2000 number, "says the report. This means that the mobile subscriber base had "disappeared" more than 1.8 million. Subscriptions. However, the market remains highly saturated with penetration per capita of nearly $145 \%$, as Mtel remains the leader with 39 percent of mobile subscribers, followed by $37 \%$ Globul and Vivacom by $24 \%$.

\section{CONCLUSION}

The undergoing transformation of the telecommunication sector in the country has impacted all three major competitors. The change in government policies and the individual company policies is focused on the realization of the actual competitive position of each player there strengths. Competitiveness of the telecommunications companies in the country will be determined by competitive bundled services and flexibility of combining them.

Administrative environment in the country favor incumbents, which is more specific to the sector than local law. Legislative and regulatory authorities should focus on investments promoting technical innovation, avoiding focusing only on the reduction of retail prices in the short term. This can only be achieved if the policies are focus on three major points:

Predictability - providing a stable regulatory environment through a systematic approach in determining the development of the sector, lack of abrupt and frequent legislative changes in time, etc .;

Proportionality - taking into account national characteristics, including the level of competition in the perception of one or another regulatory approach;

Lack of discrimination - ensuring comparable conditions of competition between operators and balanced approach to small and large companies.

\section{REFERENCES}

1. Balassa, B., An Empirical Demonstration of Classical Comparative Costs Theory, Review of Economics and Statistics, August 1963;

2. Porter, M.E., Competitive Advantage of Nations, N.Y., 1991,

3. Vollrath, T.L. (1991), "A Theoretical Evaluation of Alternative Trade Intensity Measures of Revealed Comparative Advantage", Weltwirtschaftliches Archiv, 130, 26;

4. Frohberg K. and M. Hartmann (1997) Comparing Measures of Competitiveness, IAMO discussion paper No. 2, Halle, Germany; 